Original Research Paper

\title{
Simulation and Optimization of Perovskite Type Micro Thermoelectric Generator
}

\author{
${ }^{1}$ Jeyashree Yesuraj, ${ }^{2}$ Vimala Juliet Ashokan, \\ ${ }^{3}$ Sukhi Yesuraj and ${ }^{4}$ Rebecca Shirly Harrison Christley \\ ${ }^{I}$ Department of EEE, SRM University, Chennai, India \\ ${ }^{2}$ Department of EIE, SRM University, Chennai, India \\ ${ }^{3}$ Department of EEE, RMK Engineering College, University, Chennai, India \\ ${ }^{4}$ Department of EIE, SRM University, Chennai, India
}

Article history

Received: 23-10-2015

Revised: 27-06-2016

Accepted: 21-11-2016

Corresponding Author:

Jeyashree Yesuraj

Department of EEE, SRM

University, Chennai, India

Email: jeyashree_christley@yahoo.co.in

\begin{abstract}
In this study the thermoelectric properties of perovskite type $\mathrm{Ca}-\mathrm{Mn}-\mathrm{O}_{3}$ compounds are estimated for the operating range of 850-1150 $\mathrm{K}$. The optimization of design module for maximum power output is obtained using the analytical expression for power of Thermoelectric Generator (TEG). For the optimum length of $1.4 \mu \mathrm{m}$ and with a cross sectional area of $0.3 \times 0.3 \mu \mathrm{m}$ the power obtained is $4.635 \mathrm{nW}$. For the same optimum length of $1.4 \mu \mathrm{m}$ when the cross sectional area is increased to $0.6 \times 0.6 \mu \mathrm{m}$ the power obtained is $18.54 \mathrm{nW}$. A bridge type micro TEG ( $\mu$ TEG) with two thermo couples in series and four thermocouples in parallel are simulated and the temperature and voltage distribution obtained. The variation of power density for varying the gap length is analyzed. The calculated power density is $2.75 \mathrm{~mW} /\left(\mathrm{cm}^{2} \mathrm{~K}^{2}\right)$ for optimum length of $1.4 \mu \mathrm{m}$ with a gap length of $0.3 \mu \mathrm{m}$ and cross sectional area of $0.6 \times 0.6 \mu \mathrm{m}$. The calculated power density is increased to 4.0748 $\mathrm{mW} /\left(\mathrm{cm}^{2} \mathrm{~K}^{2}\right)$ for the same optimum length of $1.4 \mu \mathrm{m}$ when the gap length is $0.1 \mu \mathrm{m}$ and with the same cross sectional area of $0.6 \times 0.6 \mu \mathrm{m}$. To power up a $75 \mathrm{~W}$ LED street light the required number of devices connected in series is 322 and in parallel is 12,658228 with the impedance matching between the micro thermoelectric generator and the load.
\end{abstract}

Keywords: Micro Thermo Electric Generator, Figure of Merit, Design Optimization, LED Lighting

\section{Introduction}

Due to the rise in energy demand and pollution control requirement, the demand for the clean energy system is increasing. Micro Thermoelectric Generators ( $\mu$ TEGs) are the clean energy sources. They utilize waste heat and convert to electricity. Glatz et al. (2009) works on Seebeck effect. When a temperature gradient exists across a material, a proportional voltage is developed and when a load is connected, electrical power is obtained. The $\mu$ TEGs have no moving parts. Xiong et al. (2011) discusses the proprrties of the device as robust and maintenance free. Kao et al. (2010) explains the function of $\mu$ TEGs is not only to generate electric power but also to recycle reuse waste heat energy. This type of generation is applied for waste heat recovery in body. Kishi et al. (1999) developed bismuth telluride based micro thermoelectric generator and utilised the heat emitted from the person's wrist. The electrical energy generated is used to power up wrist watch of $1 \mu \mathrm{W}$ with a driving voltage of $1.5 \mathrm{~V}$. Ming Chen et al. (2011) developed a poly Silicon based transparent micro thermoelectric generator and utilized the temperature difference between the inside and outside of the windows of the building. Ming Chen et al. (2011) shows that each glass window of size $60 \times 90 \mathrm{~cm}$ assembled with $\mu$ TEG can generate $0.05 \sim 0.1 \mathrm{~W}$ of electrical power with a temperature difference of $5 \sim 10 \mathrm{~K}$. Three best known groups of thermoelectric materials are bismuth telluride $\left(\mathrm{Bi}_{2} \mathrm{Te}_{3}\right)$, lead telluride and silicon-germanium alloys. In this $\mathrm{Bi}_{2} \mathrm{Te}_{3}$ has the highest figure of merit around room temperature. Lead telluride has the highest figure of merit in the temperature range $(400-800 \mathrm{~K})$. The silicongermanium alloy has the highest figure of merit at 1300 $\mathrm{K}$ (Tripathi and Bhandari, 2005; LaLonde et al., 2011). Thermoelectric generators needs high figure of merit 
merit $z T=S^{2} \sigma T /\left(k_{E} k_{L}\right)$ to be maintained over a large temperature gradient. The Seebeck coefficient(S), electrical conductivity $(\sigma)$, electronic thermal conductivity $\left(K_{E}\right)$ and lattice thermal conductivity $\left(K_{L}\right)$ are interdependent via carrier concentration. To improve $\mathrm{ZT}$, carrier concentration must be optimized and thermal conductivity must be minimized. The optimum carrier concentration increases with temperature. In Ag doped $\mathrm{PbTe} / \mathrm{Ag}_{2} \mathrm{Te}$ composite the solubility of $\mathrm{Ag}$ increases with temperature. This gives the self-tuning of the optimum carrier concentration with temperature. The lattice thermal conductivity is reduced by the $\mathrm{Ag}_{2} \mathrm{Te}$ nano precipitate. Pei et al. (2011) obtained the peak ZT as 1.24 at $750 \mathrm{~K}$ with the carrier concentration of $2 \times 10^{19}$ $\mathrm{cm}^{-3}$. The important requirements of high temperature thermoelectric materials are high chemical and thermal stability for long time (Yasukawa et al., 2010; Hamada et al., 2009; Kawakami et al., 2009; Weidenkaff et al., 2010). The material should be easy for manufacturing (Yasukawa et al., 2010; Hamada et al., 2009). Weidenkaff et al. (2010) states that the other requirements are the material should be non-toxic and environmentally friendly, easily available and light weight. Perovskite type materials have all the above requirements and are suited for thermoelectric power generation (Yasukawa et al., 2010; Hamada et al., 2009; Kawakami et al., 2009; Weidenkaff et al., 2010).

\section{Optimization of Design Module of $\mu$ TEG}

In lateral design of thermocouple with lateral heat flow the thermal coupling is less because the contact surface between the source and the $\mu$ TEG is minimum. Glatz et al. (2009) proves that vertical heat flow is improved with vertical design. Figure 1 shows the lateral design. Tripathi and Bhandari (2005) explains that radially oriented $\mu$ TEG is used for power generation from hot gas stream. Figure 2 shows the radial design. Kao et al. (2010) deals with bridge type design in which thermocouples are connected in series as well as in parallel which increases both voltage and current output of $\mu$ TEG. Figure 3 shows the bridge type design. Optimization of module geometry is required for the maximization of power output. Rowe and Min (1996) discuss the formula required to achieve an optimized module design are:

$$
\begin{aligned}
& V=N \alpha\left(T_{h}-T_{c}\right) /\left(1+2 r l_{c} / l\right) \\
& I=A \alpha\left(T_{h}-T_{c}\right) / 2 \rho(n+l)\left(1+2 r l_{c} / l\right) \\
& P=4 \alpha A N\left(T_{h}-T_{c}\right) / 2 \rho(n+l)\left(1+2 r l_{c} / l\right)
\end{aligned}
$$

where, $N$ is the number of thermocouples, $\rho$ is the electrical resistivity, $T_{h}$ and $T_{c}$ are temperatures at hot and cold side respectively, $A$ and $l$ are the area of cross section and thermo element length respectively, $l_{\mathrm{c}}$ is the contact layer thickness, $n=2 \rho_{c} / \rho$ and $r=K / K_{C}, \rho_{c}$ electrical resistivity of contact, $K_{C}$ thermal conductivity of contact layer, $l$ is the length of thermoleg, $A$ is the cross sectional area, $\alpha$ is the Seebeck coefficient of thermoleg, $\mathrm{K}$ is the thermal conductivity of thermoleg, $\rho$ is the electrical resistivity of thermoleg, $V$ is the voltage of $\mu$ TEG, $I$ is the current of $\mu$ TEG and $\mathrm{P}$ is the power of the $\mu$ TEG. A single $\mu$ TEG is analyzed using MATLAB. The cross sectional area of $\mu$ TEG is $0.3 \times 0.3 \mu \mathrm{m}$. The thermoelectric material used is perovskite-type $\mathrm{Ca}_{0.85} \mathrm{Nd}_{0.1} \square_{0.05} \mathrm{MnO}_{3}$ ( $\square$ indicates A-site vacancy). Kawakami et al. (2009) states that the thermoelectric properties of the materials are: Seebeck coefficient is $104.889 \mu \mathrm{V} / \mathrm{K}$ and the thermal conductivity is $3.3 \mathrm{~W} /(\mathrm{m}$ $\mathrm{K})$. The electrical conductivity is 17905.103 , 17655.991, $17324.17, \quad 16494.029, \quad 15830.049,14999.250$ and $14336.095 \mathrm{~S} / \mathrm{m}$ for temperature $850 \mathrm{~K}, 900,950,1000$, 1050,1100 and $1150 \mathrm{~K}$ respectively. The temperature of the hot side is varied from 850 to $1150 \mathrm{~K}$ in steps of 50 $\mathrm{K}$. The cold side temperature is $750 \mathrm{~K}$. The thickness of contact layer is $0.1 \mu \mathrm{m}$. The contact layer material used is copper and $K_{C}$ is $385 \mathrm{~W} /(\mathrm{m}-\mathrm{K}) . \mathrm{r}$ is 0.00857 . Figure 4 shows the voltage of $\mu$ TEG for varying the thermo leg length from 0 to $2.8 \mu \mathrm{m}$ in steps of $0.2 \mu \mathrm{m}$ with a cross sectional area of $0.3 \times 0.3 \mu \mathrm{m}$. Figure 5 shows the current of $\mu \mathrm{TEG}$ for varying the thermo leg length from 0 to 2.8 $\mu \mathrm{m}$ in steps of $0.2 \mu \mathrm{m}$ with a cross sectional area $0.3 \times 0.3$ $\mu \mathrm{m}$. Figure 6 shows the power of $\mu$ TEG for varying the thermo leg length from 0 to $2.8 \mu \mathrm{m}$ in steps of $0.2 \mu \mathrm{m}$

\begin{tabular}{|c|c|c|c|}
\hline \multicolumn{4}{|c|}{$0.3 \times 0.3 \mu \mathrm{m}$} \\
\hline Sl.No. & $\mathrm{T}_{\mathrm{h}}(\mathrm{K})$ & $\mathrm{P}_{\max }(\mathrm{nW})$ & $\mathrm{L}_{\mathrm{opt}}(\mu \mathrm{m})$ \\
\hline 1. & 850 & 0.2898 & $1.2-1.8$ \\
\hline 2. & 900 & 0.6521 & $1.2-1.6$ \\
\hline 3. & 950 & 1.1590 & $1.0-2.4$ \\
\hline 4. & 1000 & 1.8110 & $1.0-2.0$ \\
\hline 5. & 1050 & 2.6080 & $1.2-1.6$ \\
\hline 6. & 1100 & 3.5490 & $1.2-1.6$ \\
\hline 7. & 1150 & 4.6350 & $1.2-1.4$ \\
\hline
\end{tabular}
with a cross sectional area of $0.3 \times 0.3 \mu \mathrm{m}$.

Table 1. Performance of $\mu$ TEG with a cross sectional area of

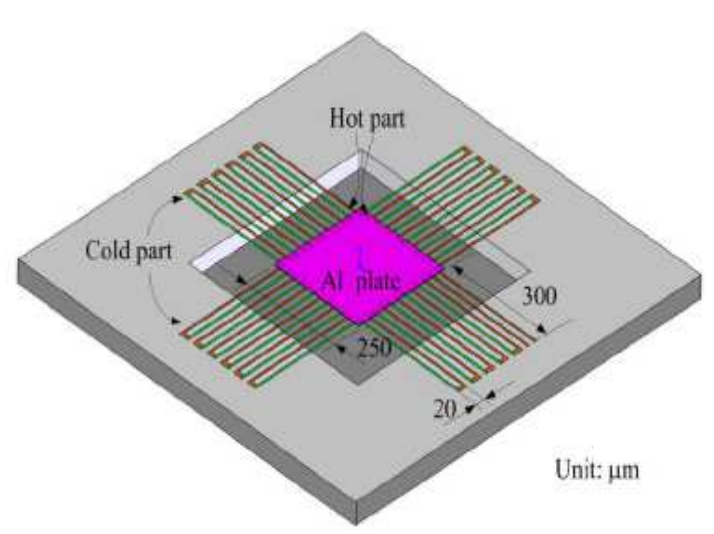

Fig. 1. Lateral design (Kao et al., 2010) 


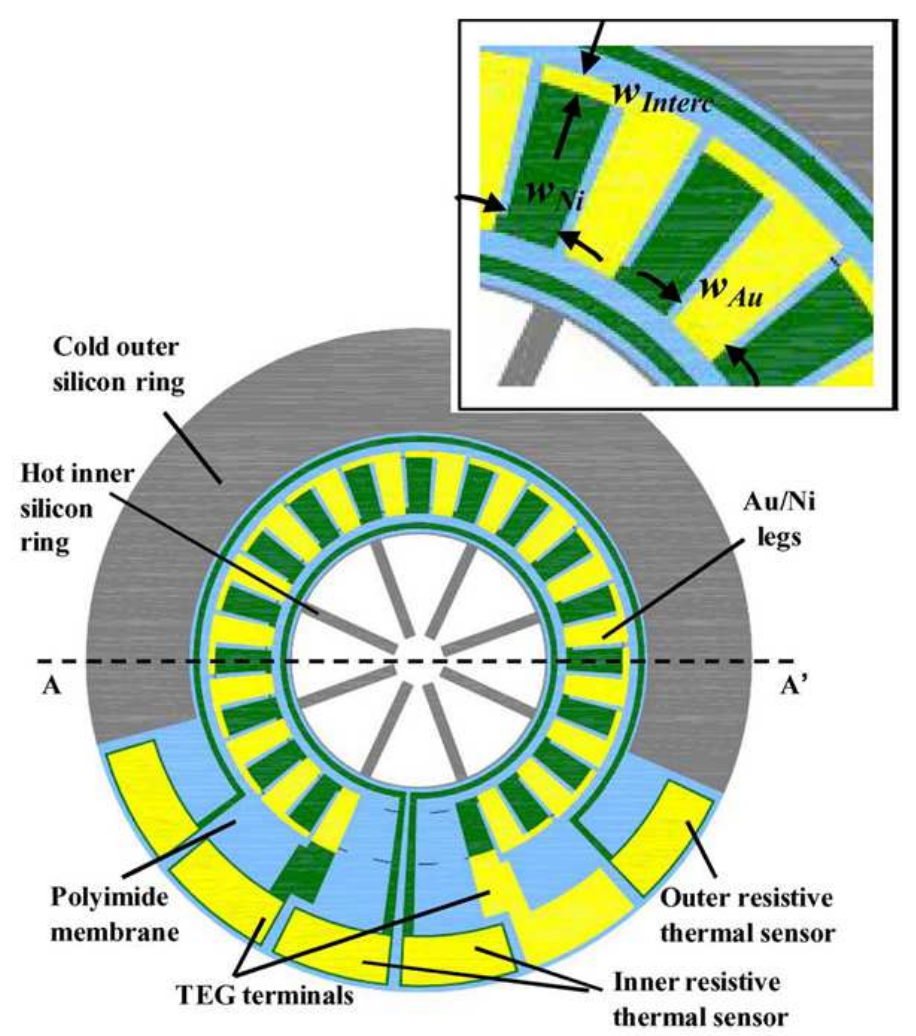

Fig. 2. Radial design (Xiong et al., 2011)

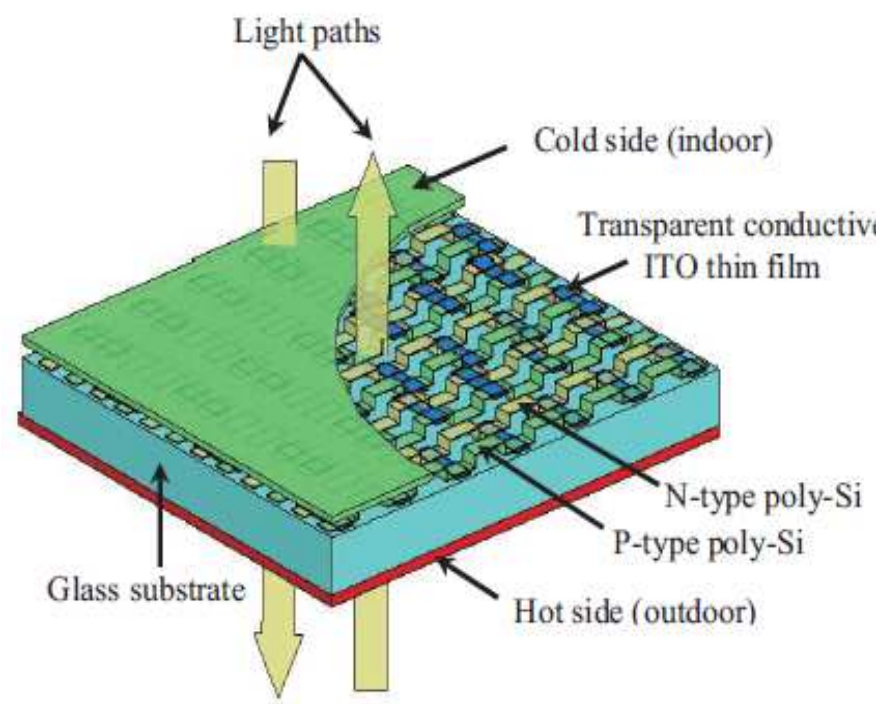

Fig. 3. Bridge design (Ming Chen et al., 2011)

Optimum length is the length of a thermo leg for which the power obtained is maximum for a particular operating temperature. For each operating temperature the optimum length is 1.2 to $1.4 \mu \mathrm{m}$ with a cross sectional area of $0.3 \times 0.3 \mu \mathrm{m}$. Table 1 gives the maximum power output and the optimum length for hot side temperature varying from 850 to $1150 \mathrm{~K}$ in steps of $50 \mathrm{~K}$ with a cross sectional area of $0.3 \times 0.3 \mu \mathrm{m}$. The cross sectional area of $\mu \mathrm{TEG}$ is increased as $0.4 \times 0.4 \mu \mathrm{m}$.

Figure 8 shows the current of $\mu$ TEG for varying the thermo leg length from 0 to $2.8 \mu \mathrm{m}$ in steps of $0.2 \mu \mathrm{m}$ with a cross sectional area of $0.4 \times 0.4 \mu \mathrm{m}$. 


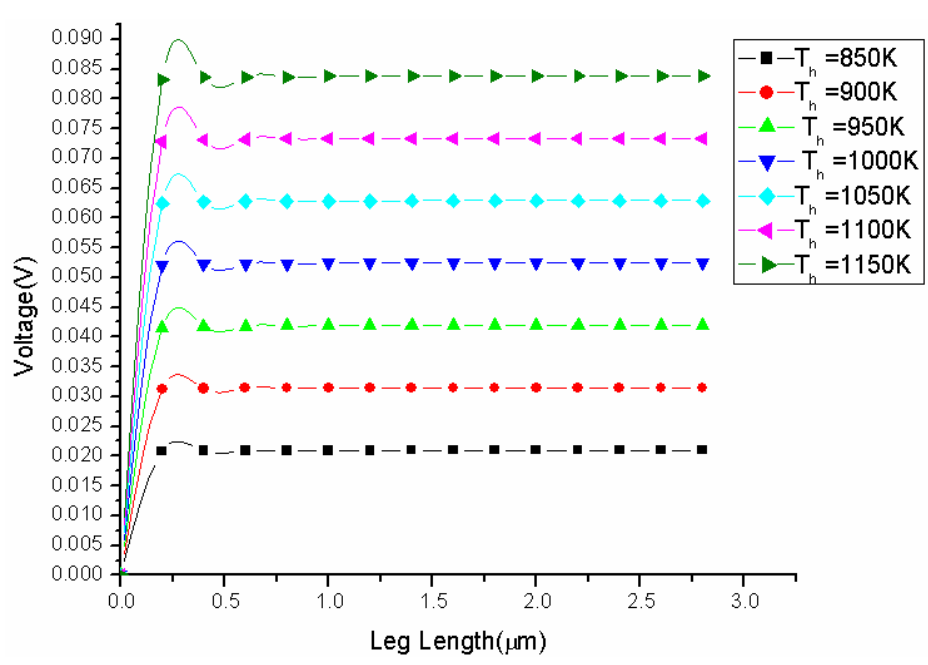

Fig. 4. Voltage of $\mu$ TEG for varying the thermo leg length with a cross sectional area of $0.3 \times 0.3 \mu \mathrm{m}$

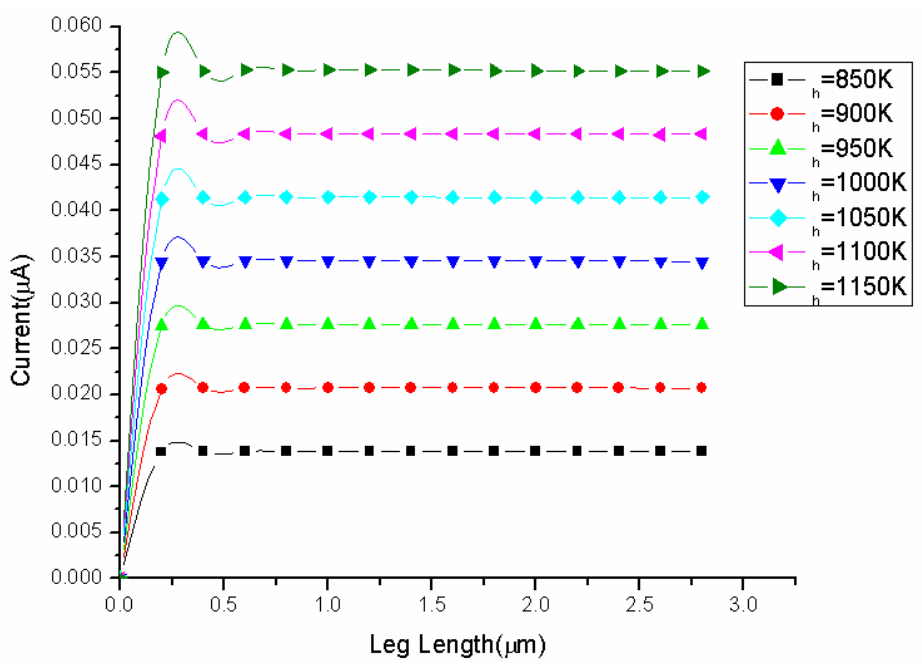

Fig. 5. Current of $\mu$ TEG for varying the thermo leg length with a cross sectional area of $0.3 \times 0.3 \mu \mathrm{m}$

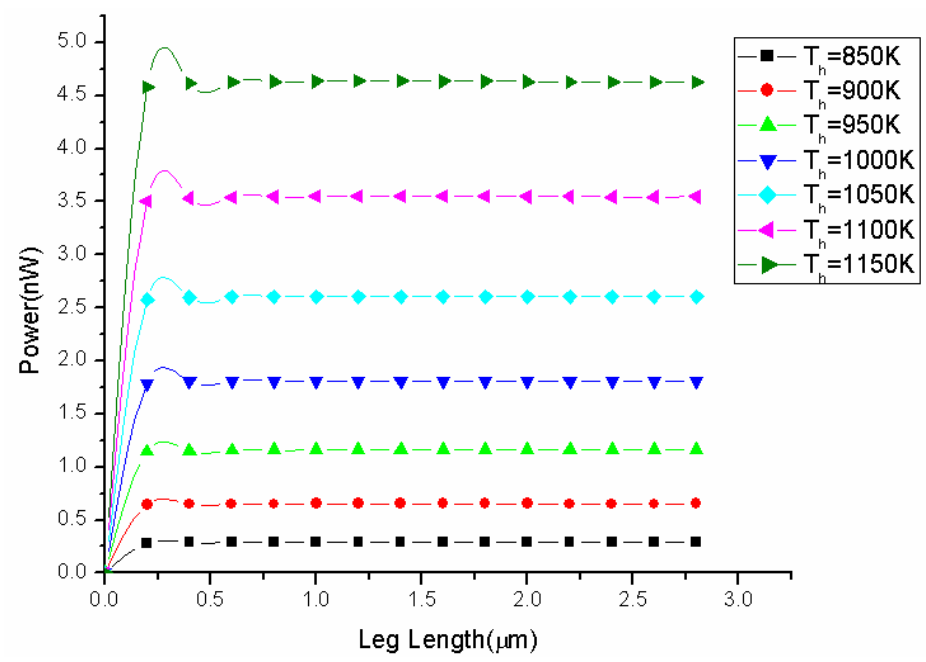

Fig. 6. Power of $\mu$ TEG for varying the thermo leg length with a cross sectional area of $0.3 \times 0.3 \mu \mathrm{m}$ 


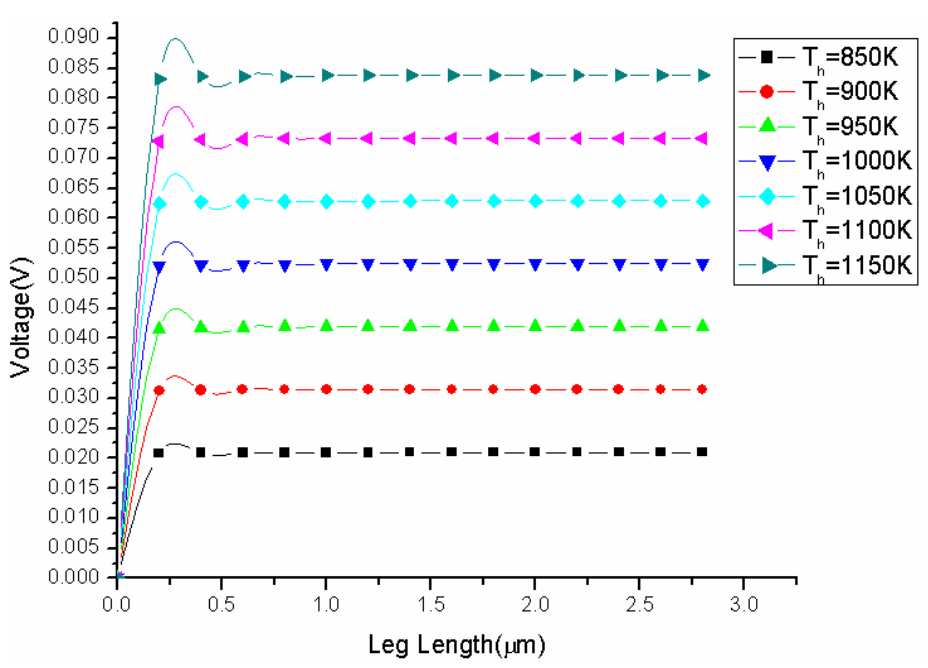

Fig. 7. Voltage of $\mu$ TEG for varying the thermo leg length with a cross sectional area of $0.4 \times 0.4 \mu \mathrm{m}$

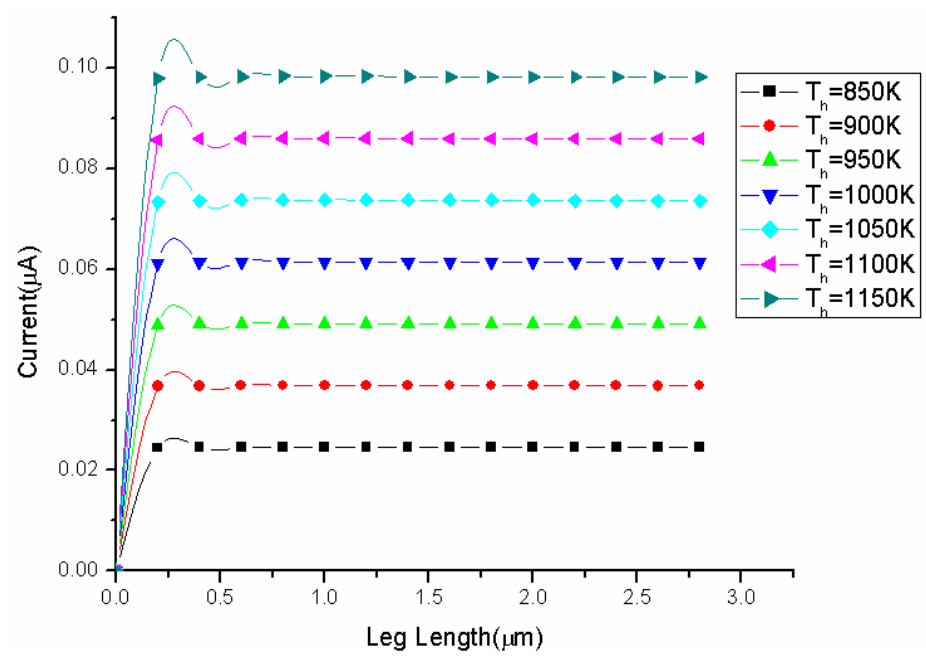

Fig. 8. Current of $\mu$ TEG for varying the thermo leg length with a cross sectional area of $0.4 \times 0.4 \mu \mathrm{m}$

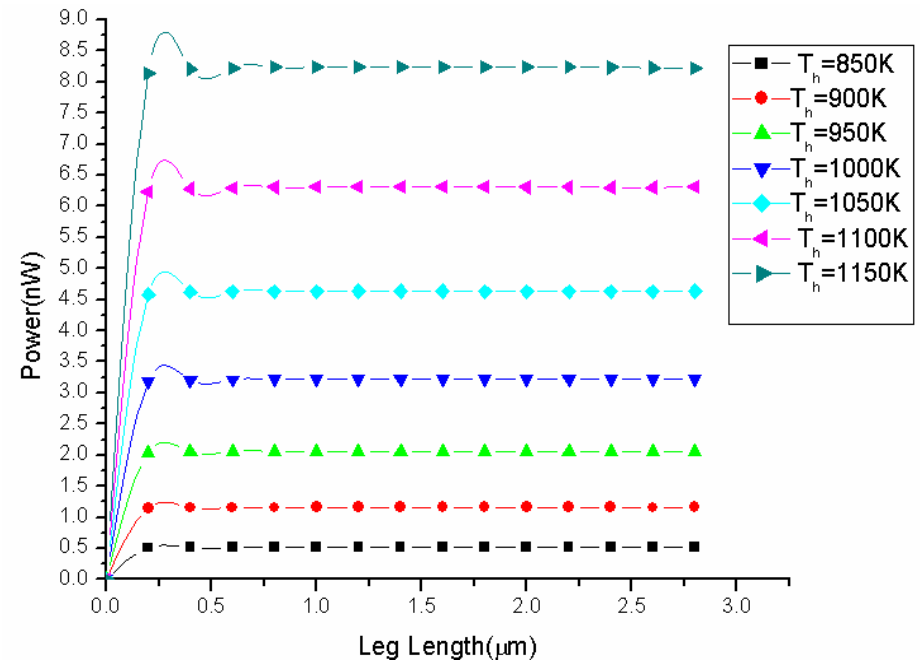

Fig. 9. Power of $\mu$ TEG for varying the thermo leg length with a cross sectional area of $0.4 \times 0.4 \mu \mathrm{m}$ 


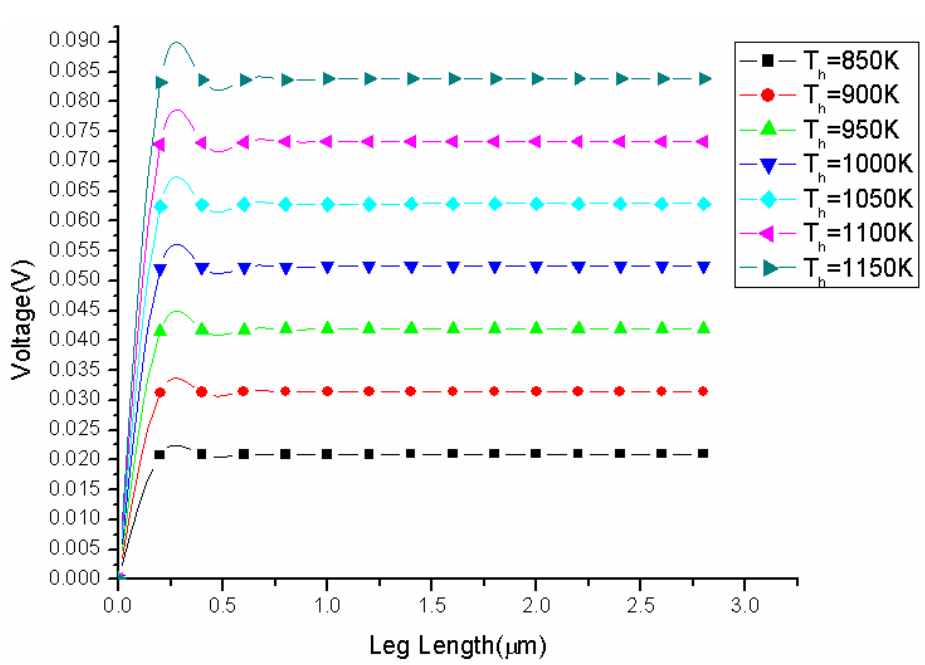

Fig. 10. Voltage of $\mu$ TEG for varying the thermo leg length with a cross sectional area of $0.5 \times 0.5 \mu \mathrm{m}$

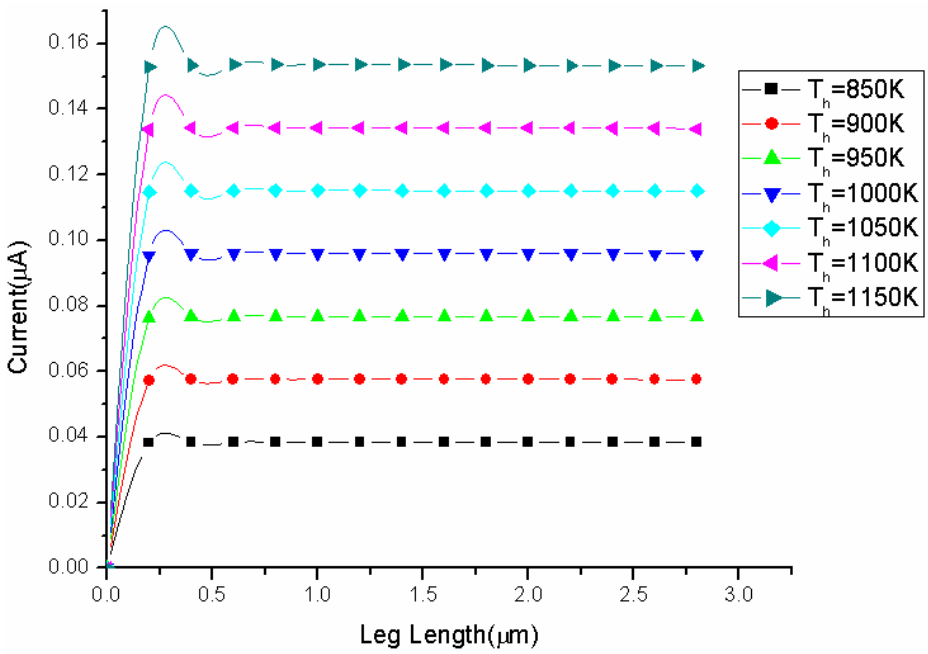

Fig. 11. Current of $\mu$ TEG for varying the thermo leg length with a cross sectional area of $0.5 \times 0.5 \mu \mathrm{m}$

Table 2. Performance of $\mu$ TEG with a cross sectional area of

\begin{tabular}{lrll}
\multicolumn{5}{c}{$0.4 \times 0.4 \mu \mathrm{m}$} \\
\hline Sl. No. & $\mathrm{T}_{\mathrm{h}}(\mathrm{K})$ & $\mathrm{P}_{\max }(\mathrm{nW})$ & $\mathrm{L}_{\text {opt }}(\mu \mathrm{m})$ \\
\hline 1. & 850 & 0.5153 & $1.4-1.6$ \\
2. & 900 & 1.1590 & $1.0-2.4$ \\
3. & 950 & 2.0610 & $1.2-1.6$ \\
4. & 1000 & 3.2200 & $1.2-1.6$ \\
5. & 1050 & 4.6360 & $1.2-1.6$ \\
6. & 1100 & 6.3090 & $1.2-1.6$ \\
7. & 1150 & 8.2400 & $1.2-1.4$ \\
\hline
\end{tabular}

The same thermoelectric material is used and the same thermoelectric properties are used. Figure 7 shows the voltage of $\mu$ TEG for varying the thermo leg length from 0 to $2.8 \mu \mathrm{m}$ in steps of $0.2 \mu \mathrm{m}$ with a cross sectional area of $0.4 \times 0.4 \mu \mathrm{m}$. Figure 9 shows the power of $\mu$ TEG for varying the thermo leg length from 0 to $2.8 \mu \mathrm{m}$ in steps of $0.2 \mu \mathrm{m}$ with a cross sectional area of $0.4 \times 0.4 \mu \mathrm{m}$. For each operating temperature the optimum length is 1.2 to $1.4 \mu \mathrm{m}$ with a cross sectional area of $0.4 \times 0.4 \mu \mathrm{m}$. Table 2 gives the maximum power output and the optimum length for hot side temperature varying from 850 to $1150 \mathrm{~K}$ in steps of $50 \mathrm{~K}$ with a cross sectional area of $0.4 \times 0.4 \mu \mathrm{m}$.

The cross sectional area of $\mu \mathrm{TEG}$ is increased as $0.5 \times 0.5 \mu \mathrm{m}$. The same thermoelectric material and its properties are used. The temperature of the hot side is varied from 850 to $1150 \mathrm{~K}$ in steps of $50 \mathrm{~K}$. The cold side temperature is $750 \mathrm{~K}$. Figure 10 shows the voltage of $\mu \mathrm{TEG}$ for varying the thermo leg length from 0 to $2.8 \mu \mathrm{m}$ in steps of $0.2 \mu \mathrm{m}$ with a cross sectional area of $0.5 \times 0.5 \mu \mathrm{m}$.

Figure 11 shows the current of $\mu \mathrm{TEG}$ for varying the thermo leg length from 0 to $2.8 \mu \mathrm{m}$ in steps of $0.2 \mu \mathrm{m}$ with a cross sectional area of $0.5 \times 0.5 \mu \mathrm{m}$. Figure 12 
shows the power of $\mu$ TEG for varying the thermo leg length from 0 to $2.8 \mu \mathrm{m}$ in steps of $0.2 \mu \mathrm{m}$ with a cross sectional area of $0.5 \times 0.5 \mu \mathrm{m}$. For each operating temperature the optimum length varies from 1.2 to 1.4 $\mu \mathrm{m}$ with a cross sectional area of $0.5 \times 0.5 \mu \mathrm{m}$.

Table 3 gives the maximum power output and the optimum length for hot side temperature varying from 850 to $1150 \mathrm{~K}$ in steps of $50 \mathrm{~K}$ with a cross sectional area of $0.5 \times 0.5 \mu \mathrm{m}$. The cross sectional area of $\mu \mathrm{TEG}$ is increased as $0.6 \times 0.6 \mu \mathrm{m}$. Kawakami et al. (2009) uses the same thermoelectric material with the same thermoelectric properties. The temperature of the hot side is varied from 850 to $1150 \mathrm{~K}$ in steps of $50 \mathrm{~K}$. The cold side temperature is $750 \mathrm{~K}$. Figure 13 shows the voltage of $\mu$ TEG for varying the thermo leg length from 0 to $2.8 \mu \mathrm{m}$ in steps of $0.2 \mu \mathrm{m}$ with a cross sectional area of $0.6 \times 0.6 \mu \mathrm{m}$. Figure 14 shows the current of $\mu \mathrm{TEG}$ for varying the thermo leg length from 0 to $2.8 \mu \mathrm{m}$ in steps of $0.2 \mu \mathrm{m}$ with a cross sectional area of $0.6 \times 0.6 \mu \mathrm{m}$. Figure 15 shows the power of $\mu \mathrm{TEG}$ for varying the thermo leg length from 0 to $2.8 \mu \mathrm{m}$ in steps of $0.2 \mu \mathrm{m}$ with a cross sectional area of $0.6 \times 0.6 \mu \mathrm{m}$. For each operating temperature the optimum length is $1.4 \mu \mathrm{m}$ with a cross sectional area of $0.6 \times 0.6 \mu \mathrm{m}$.

Table 3. Performance of $\mu$ TEG with a cross sectional area of

\begin{tabular}{lcll}
\multicolumn{4}{c}{$0.5 \times 0.5 \mu \mathrm{m}$} \\
\hline S1.No. & $\mathrm{T}_{\mathrm{h}}(\mathrm{K})$ & $\mathrm{P}_{\max }(\mathrm{nW})$ & $\mathrm{L}_{\text {opt }}(\mu \mathrm{m})$ \\
\hline 1. & 850 & 0.8015 & $1.2-1.6$ \\
2. & 900 & 1.8110 & $1.0-2.2$ \\
3. & 950 & 3.2200 & $1.2-1.8$ \\
4. & 1000 & 5.0310 & $1.2-1.6$ \\
5. & 1050 & 7.2440 & $1.2-1.4$ \\
6. & 1100 & 9.8580 & $1.2-1.4$ \\
7. & 1150 & 12.870 & $0.8-1.8$ \\
\hline
\end{tabular}

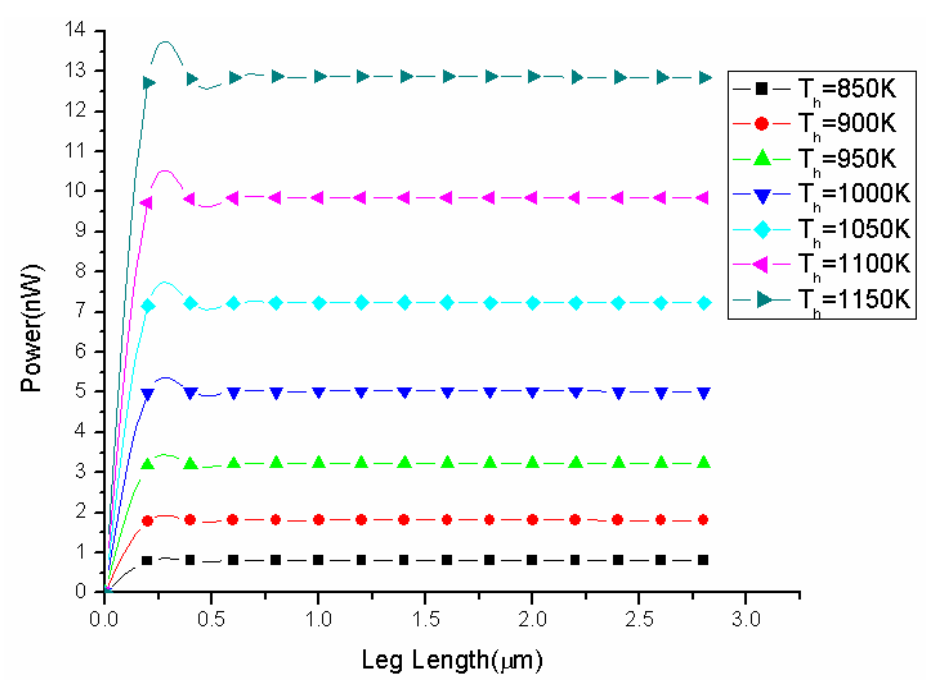

Fig. 12. Power of $\mu$ TEG for varying the thermo leg length with a cross sectional area of $0.5 \times 0.5 \mu \mathrm{m}$

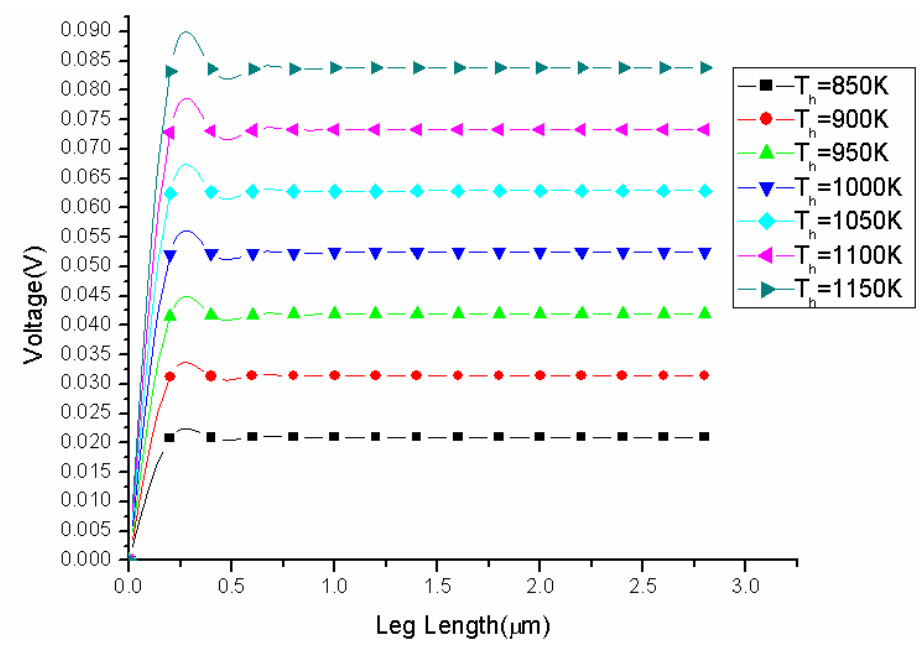

Fig. 13. Voltage of $\mu$ TEG for varying the thermo leg length with a cross sectional area of $0.6 \times 0.6 \mu \mathrm{m}$ 


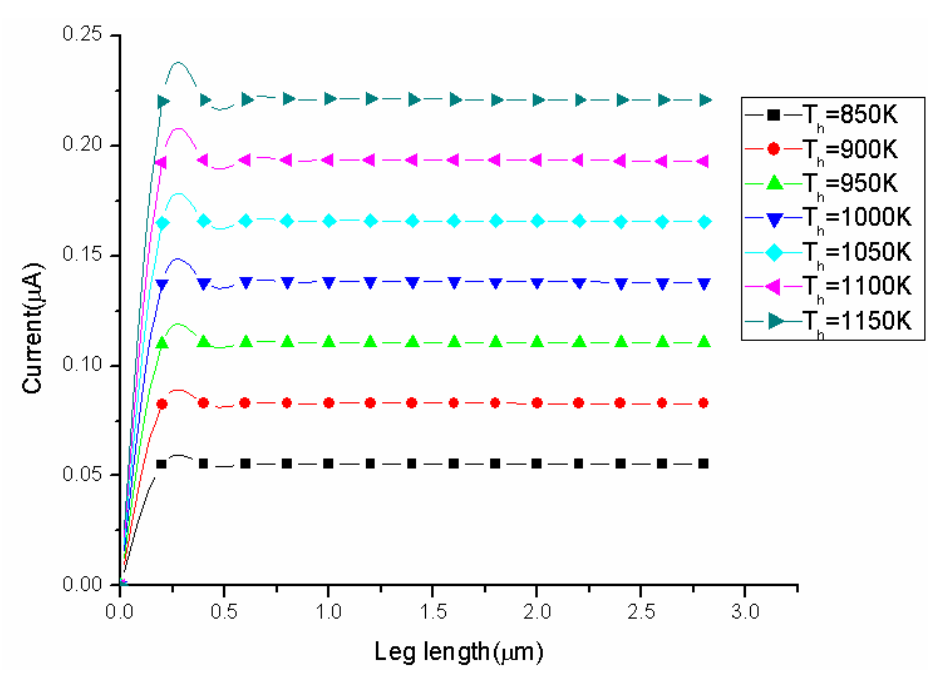

Fig.14. Current of $\mu$ TEG for varying the thermo leg length with a cross sectional area of $0.6 \times 0.6 \mu \mathrm{m}$

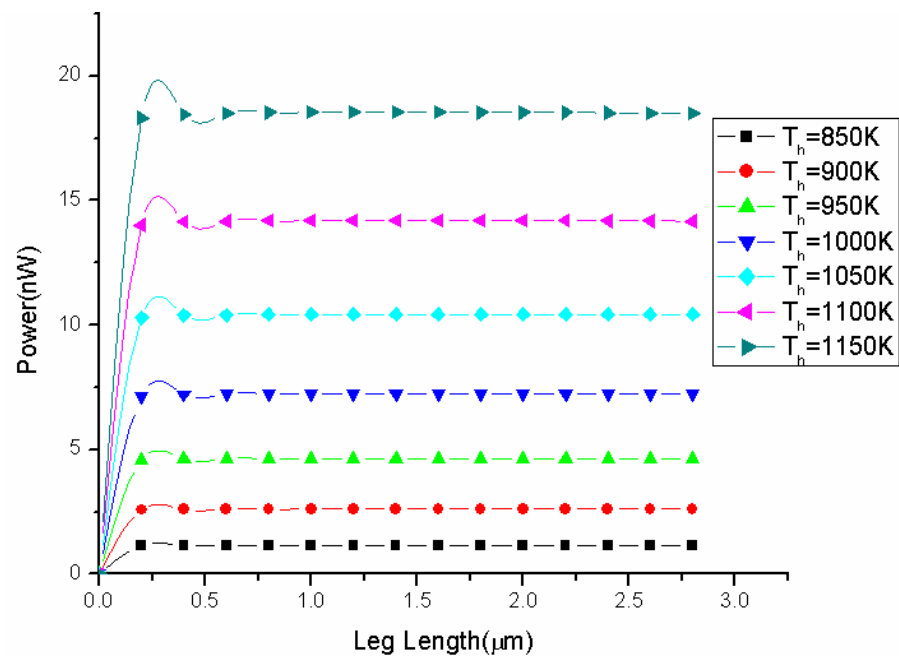

Fig. 15. Power of $\mu$ TEG for varying the thermo leg length with a cross sectional area of $0.6 \times 0.6 \mu \mathrm{m}$

Table 4. Performance of $\mu$ TEG with a cross sectional area of $0.6 \times 0.6 \mu \mathrm{m}$

\begin{tabular}{lccl}
\hline Sl. No. & $\mathrm{T}_{\mathrm{h}}(\mathrm{K})$ & $\mathrm{P}_{\max }(\mathrm{nW})$ & $\mathrm{L}_{\mathrm{opt}}(\mu \mathrm{m})$ \\
\hline 1. & 850 & 1.159 & $1-2.4$ \\
2. & 900 & 2.609 & 1.4 \\
3. & 950 & 4.637 & $1.2-1.8$ \\
4. & 1000 & 7.245 & 1.4 \\
5. & 1050 & 10.430 & $1.0-2.2$ \\
6. & 1100 & 14.200 & $1.2-1.4$ \\
7. & 1150 & 18.540 & $1.0-1.6$ \\
\hline
\end{tabular}

Table 4 gives the maximum power output and the optimum length for hot side temperature varying from 850 to $1150 \mathrm{~K}$ in steps of $50 \mathrm{~K}$ with a cross sectional area of $0.6 \times 0.6 \mu \mathrm{m}$.

For each operating temperature the optimum length is $1.4 \mu \mathrm{m}$. Modern lighting system is LED lighting to save power consumption. So the load is considered as $75 \mathrm{~W}$ LED street light. It consist of 9 LEDs in series and 8 such parallel path. The voltage and current rating of each LED is $3 \mathrm{~V}$ and $350 \mathrm{~mA}$ respectively. Resistance of each device, each path and the total are 8.57, 771.43 and 9.6 $\Omega$ respectively. To get the maximum power at the load, the resistance of micro thermoelectric generator source resistance should be equal to the load resistance. Voltage of each device is calculated as $0.0838 \mathrm{~V}$. Current in each device is calculated as $0.2212 \mu \mathrm{A}$. From this the resistance of each device is calculated as $378842.68 \Omega$. Number of devices in series is 322 to get the required voltage of $27 \mathrm{~V}$. Number of devices in parallel to get a current of $2800 \mathrm{~mA}$ is 12658228 . This gives an effective resistance of $9.6 \Omega$ which is matched with load impedance. The area required for the $\mu \mathrm{TEG}$ is $450.8 \mu \mathrm{m}$ $\times 17.7215 \mathrm{~m}$ for $75 \mathrm{~W}$ LED light. 


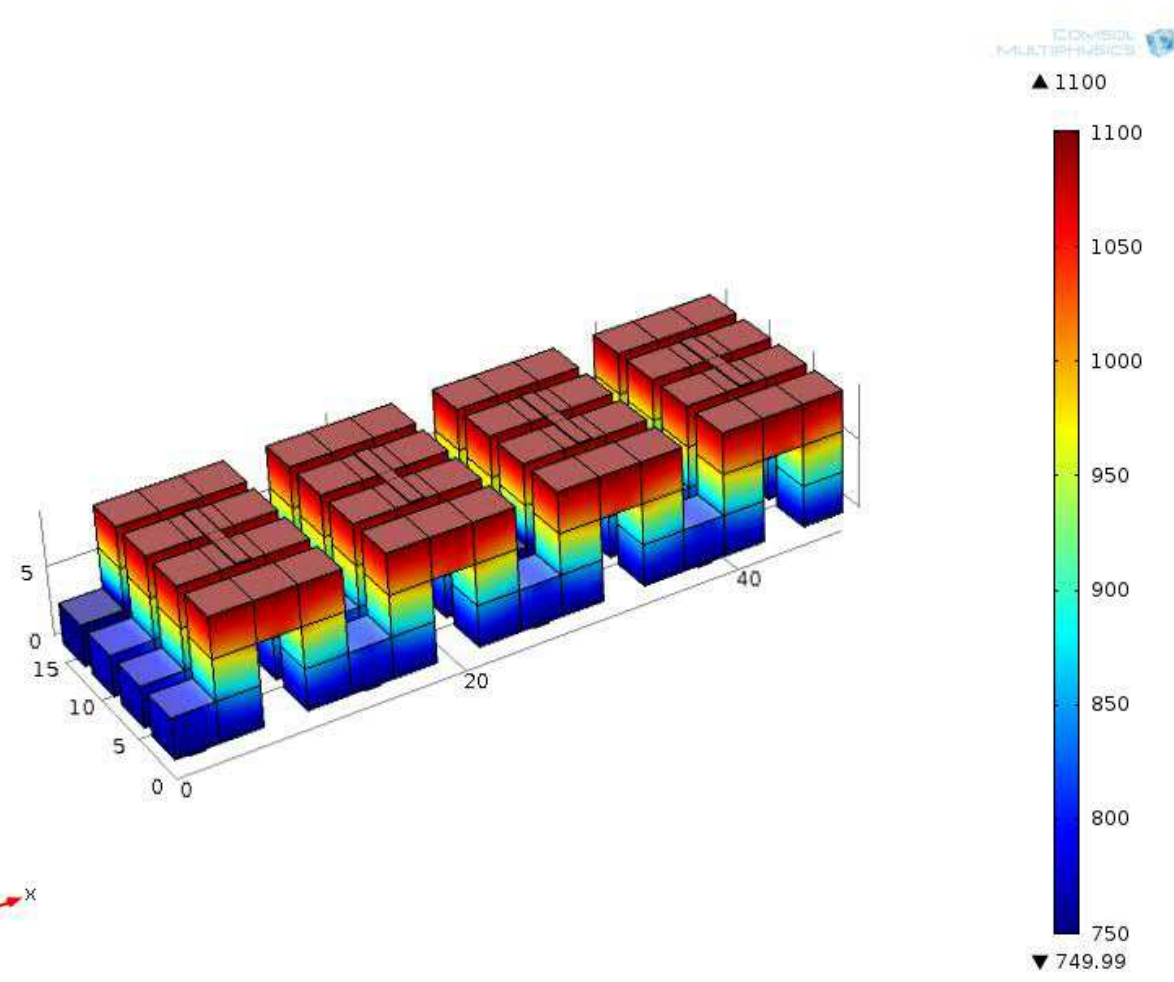

Fig. 16. Temperature distribution of $\mu \mathrm{TEG}$ with gap length of $0.3 \mu \mathrm{m}$ and leg length of $1.1 \mu \mathrm{m}$ and cross sectional area of $0.3 \times 0.3 \mu \mathrm{m}$

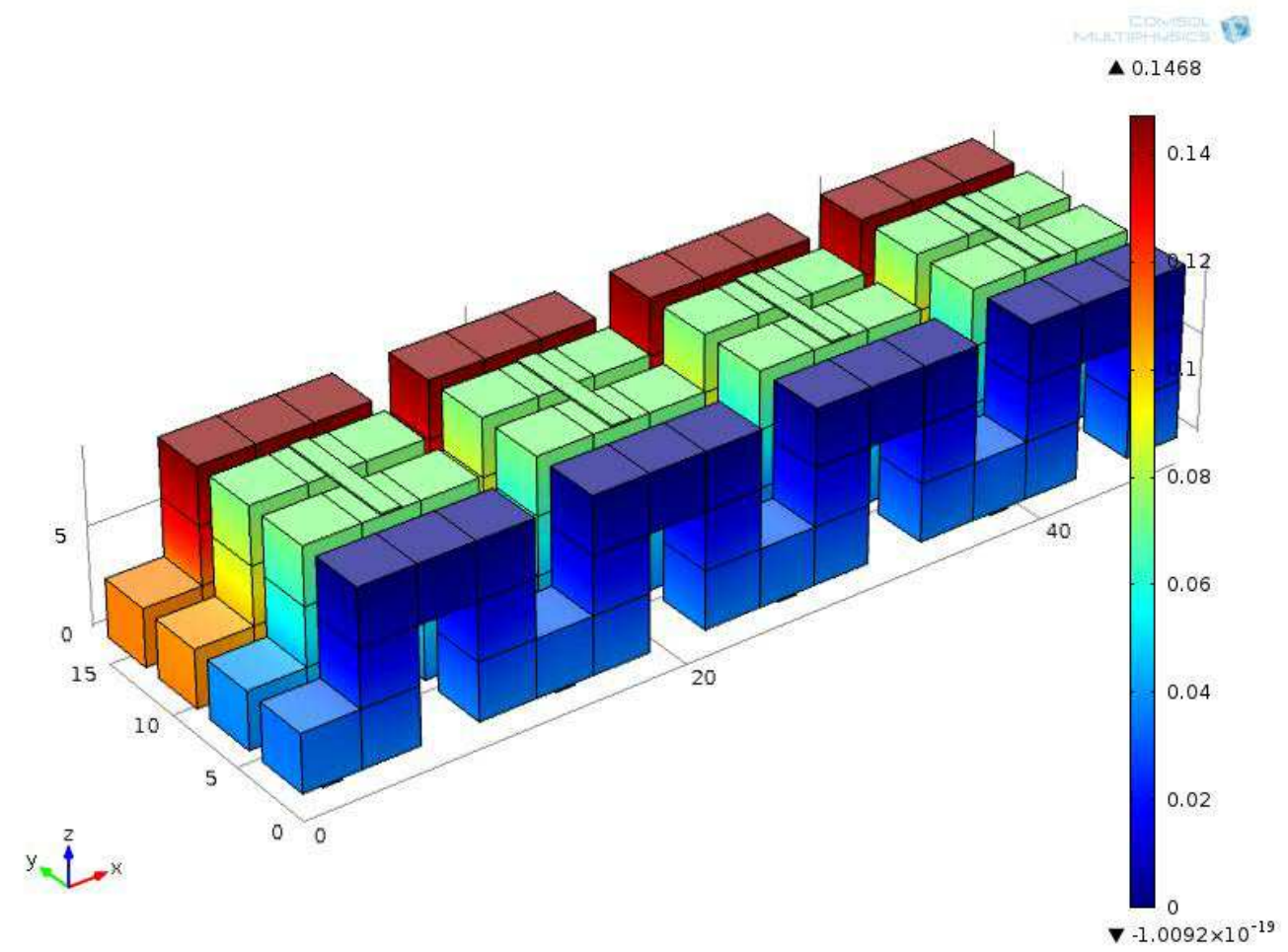

Fig. 17. Shows the voltage distribution of $\mu \mathrm{TEG}$ with gap length of $0.3 \mu \mathrm{m}$ and leg length of $1.1 \mu \mathrm{m}$ and cross sectional area of $0.3 \times 0.3 \mu \mathrm{m}$ 


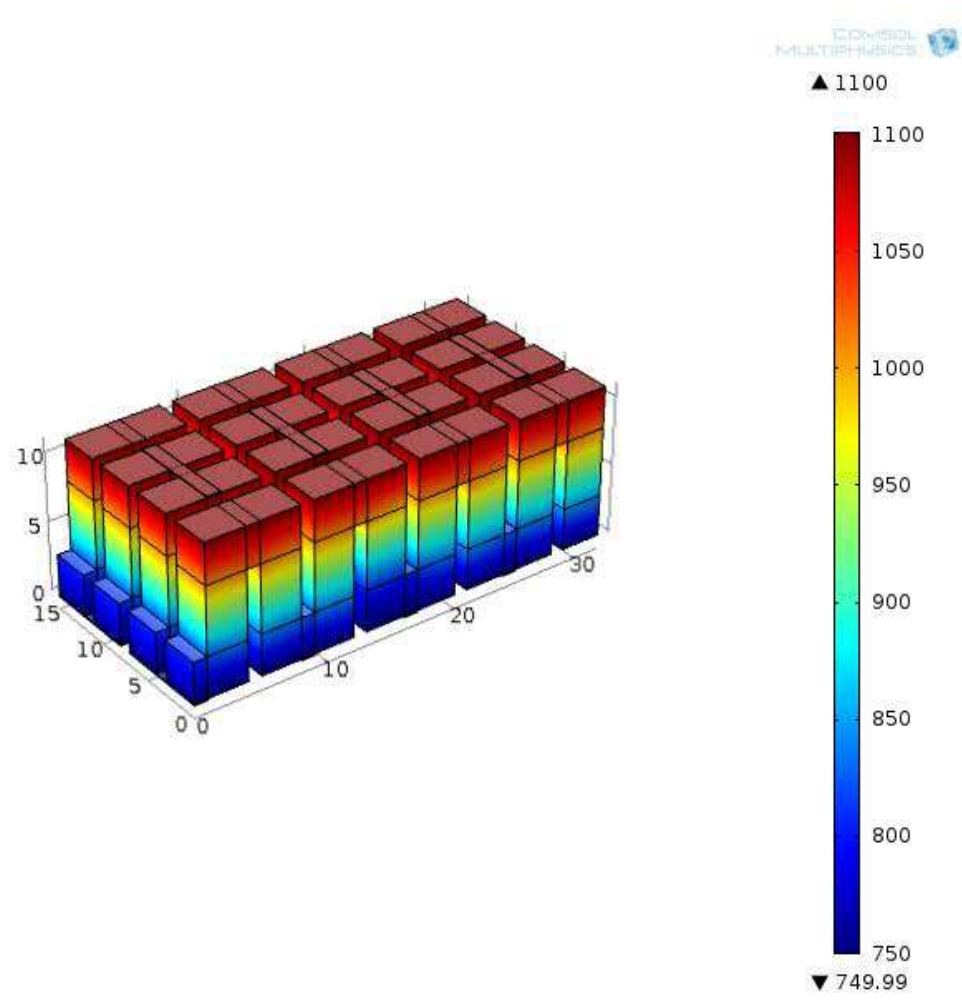

Fig. 18. Temperature distribution of $\mu$ TEG with gap length of $0.1 \mu \mathrm{m}$ and leg length of $1.3 \mu \mathrm{m}$ and cross sectional area of $0.3 \times 0.3 \mu \mathrm{m}$

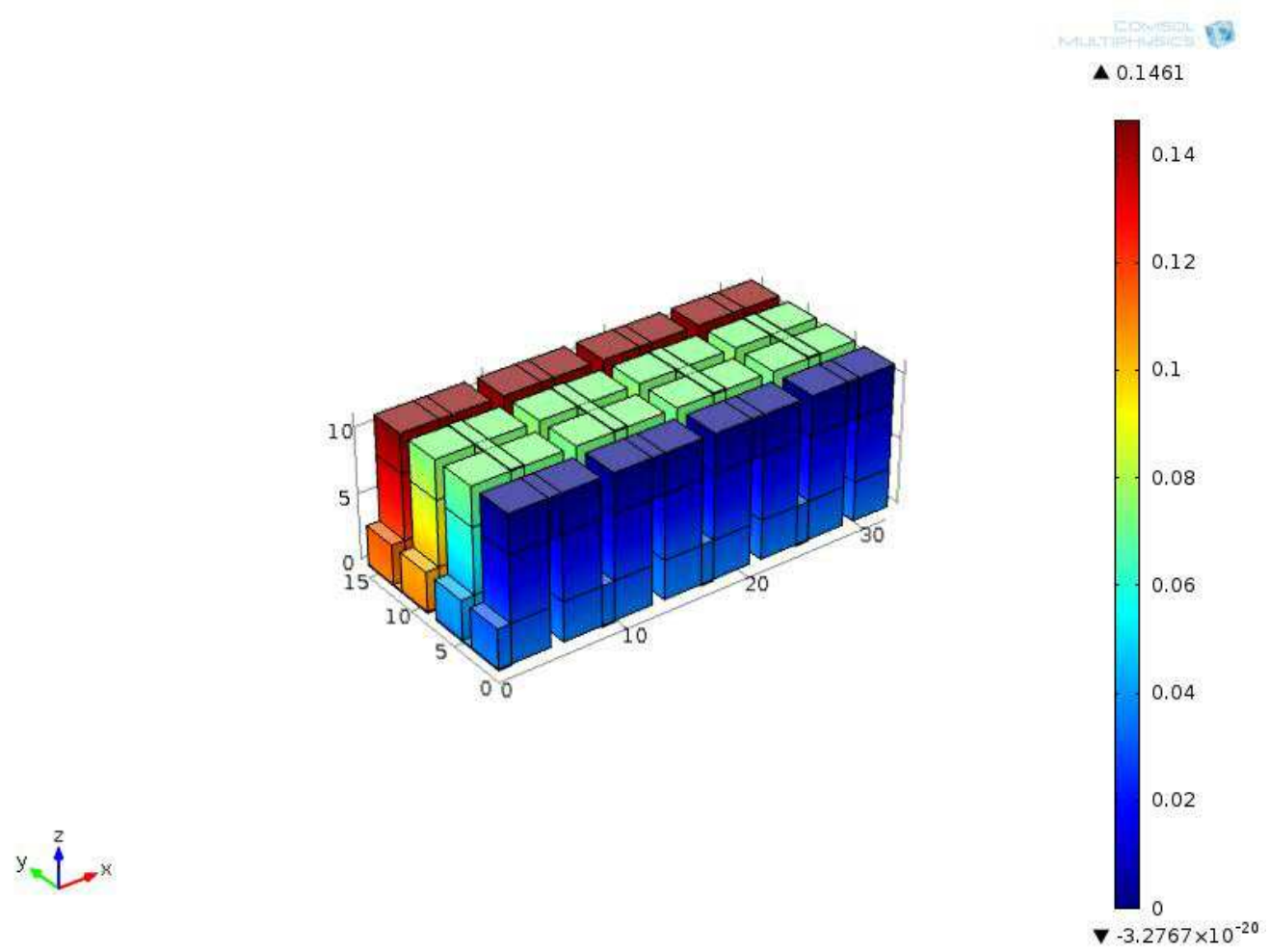

Fig. 19. Voltage distribution of $\mu \mathrm{TEG}$ with gap length of $0.1 \mu \mathrm{m}$ and leg length of $1.3 \mu \mathrm{m}$ and cross sectional area of $0.3 \times 0.3 \mu \mathrm{m}$ 


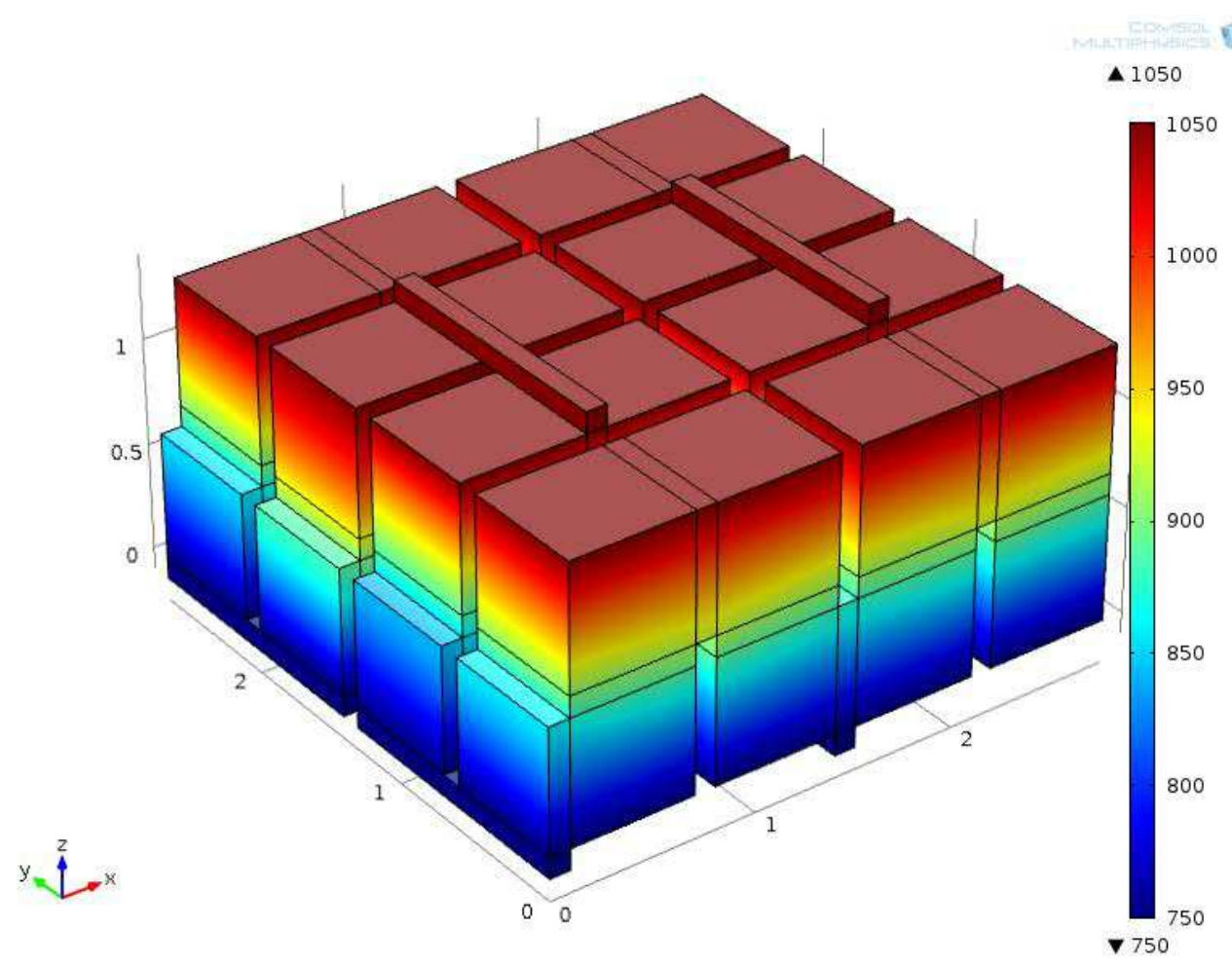

Fig. 20. Temperature distribution of $\mu$ TEG with gap length of $0.1 \mu \mathrm{m}$ and leg length of $1.3 \mu \mathrm{m}$ and cross sectional area of $0.6 \times 0.6 \mu \mathrm{m}$

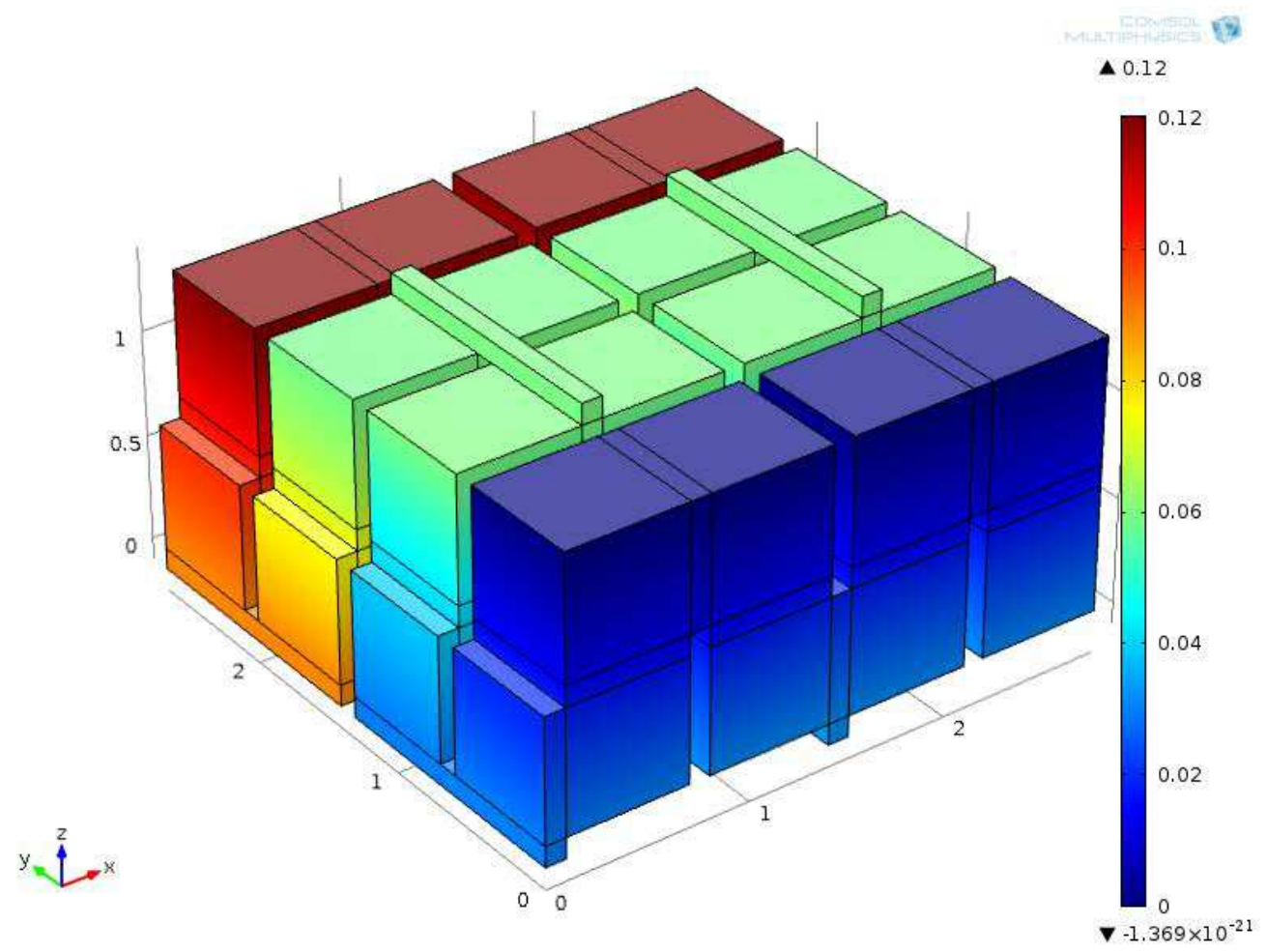

Fig. 21. Shows the voltage distribution of $\mu$ TEG with gap length of $0.1 \mu \mathrm{m}$ and leg length of $1.3 \mu \mathrm{m}$ and cross sectional area of $0.6 \times 0.6 \mu \mathrm{m}$ 


\section{Simulation of $\mu$ TEG using COMSOL}

A bridge type design of $\mu \mathrm{TEG}$ with two thermocouples in series and four parallel paths is simulated using COMSOL. The optimum length of TEG is $1.4 \mu \mathrm{m}$. The thermoelectric material used is perovskite -type $\mathrm{Ca}_{0.85} \mathrm{Nd}_{0.1} \square_{0.05} \mathrm{MnO}_{3}$.

The thermoelectric properties of the materials are Seebeck coefficient is $104.889 \mu \mathrm{V} / \mathrm{K}$. The electrical conductivity of perovskite-type $\mathrm{Ca}_{0.85} \mathrm{Nd}_{0.1} \square_{0.05} \mathrm{MnO}_{3}$ is 14336.095 S/m. The thermal conductivity of perovskitetype $\mathrm{Ca}_{0.85} \mathrm{Nd}_{0.1} \square_{0.05} \mathrm{MnO}_{3}$ is $3.3 \mathrm{~W} /(\mathrm{m}-\mathrm{K})$. The temperature of the hot side is kept at $1150 \mathrm{~K}$. The cold side temperature is $750 \mathrm{~K}$. Figure 16 shows the temperature distribution of $\mu$ TEG with gap length of $0.3 \mu \mathrm{m}$ and leg length of $1.1 \mu \mathrm{m}$ and cross sectional area of $0.3 \times 0.3 \mu \mathrm{m}$. Figure 17 shows the voltage distribution for the same $\mu$ TEG. The power density is increased by decreasing the die area. This is achieved by decreasing the gap length between the thermo leg and increasing the length of thermo leg.

Figure 18 shows the temperature distribution of $\mu$ TEG with gap length of $0.1 \mu \mathrm{m}$ and leg length of 1.3 $\mu \mathrm{m}$ and cross sectional area of $0.3 \times 0.3 \mu \mathrm{m}$. Figure 19 shows the voltage distribution for the same $\mu$ TEG. The power output is increased by increased by increasing the cross sectional area for the same optimum length. Figure 20 shows the temperature distribution of $\mu$ TEG with gap length of $0.1 \mu \mathrm{m}$ and leg length of $1.3 \mu \mathrm{m}$ and cross sectional area of $0.6 \times 0.6 \mu \mathrm{m}$. Figure 21 shows the voltage distribution for the same $\mu \mathrm{TEG}$.

\section{Conclusion}

The impedance matching for the load is obtained by series and parallel connection of micro thermoelectric generator. The power density is increased by decreasing the die area. This is achieved by decreasing the gap length between the thermo leg and increasing the length of thermo leg. The design optimization of bridge type is done for maximum power output. The thermo leg length is varied for the maximum power output. For the optimum length the power output further increases with increasing cross sectional area. The cross sectional area is then obtained for the possible bridge design. The temperature gradient can be improved by including micro fluidic heat transfer system.

\section{Acknowledgment}

I thank National Programme on Micro and Smart Systems (NPMASS) for establishing MEMS Design Centre at our University. The above simulations were done with the help of COMSOL software in the MEMS design centre.

\section{Funding Information}

The authors have no support or funding to report.

\section{Author's Contributions}

Jeyashree Yesuraj: Participated in simulation of micro thermoelectric generator using COMSOL.

Vimala Juliet Ashokan: Participated in selection of material.

Sukhi Yesuraj: Contributed for writing the manuscript.

Rebecca Shirly Harrison Christley: Participated in optimization of design of micro thermoelectric generator.

\section{Ethics}

This article is original and contains unpublished material. The corresponding author confirms that all of the other authors have read and approved the manuscript and no ethical issues involved.

\section{References}

Glatz, W., E. Schwyter, L. Durrer and C. Hierold, 2009. $\mathrm{Bi}_{2} \mathrm{Te}_{3}$-based flexible micro thermoelectric generator with optimized design. J. Microelectromech. Syst., 18: 763-772. DOI: 10.1109/JMEMS.2009.2021104

Hamada, Y., M. Yasukawa, T. Kono, K. Ueda and H. Yanagi et al., 2009. High-temperature thermoelectric properties of la-doped ba1-x $\mathrm{SrSnO}_{3}$ ceramics. J. Japan Society Powder Power Metallurgy, 56: 555-560.

Kao, P.H., P.J. Shih, C.L. Dai and M.C. Liu, 2010. Fabrication and characterization of CMOS-MEMS thermoelectric micro generators. Sensor, 10: 1315-1325. DOI: $10.3390 / \mathrm{s} 100201315$

Kawakami, H., H. Noda, M. Sugimoto, T. Takayama and H. Yamamura, 2009. Thermoelectric properties of perovskite-type related compounds Ca-Mn-O systems. Trans. Mater. Res. Society Japan, 34: 245 248. DOI: $10.14723 /$ tmrsj.34.245

Kishi, M., H. Nemoto, T. Hamao, M. Yamimoto and S. Sudou et al., 1999. Micro thermoelectric modules and their application to wristwatches as an energy source. Proceedings of the 18th International Conference on Thermoelectrics, Aug. 29-Sept. 2, IEEE Xplore Press, Baltimore, MD, USA., pp: 301-307. DOI: $10.1109 /$ ICT.1999.843389

LaLonde, A.D., Y. Pei, H. Wang and G.J. Snyder, 2011. Lead telluride alloy thermoelectrics. Mater. Today, 14: 526-532. DOI: 10.1016/S1369-7021(11)70278-4

Ming Chen, G., I.Y. Huang, L.Y. Ma and T.E. Wu, 2011. Development of a novel transparent microthermoelectric generator for solar energy conversion. Proceedings of the IEEE International Conference on Nano/Micro Engineered and Molecular Systems, Feb. 20-23, IEEE Xplore Press, Kaohsiung, pp: 976-979. DOI: 10.1109/NEMS.2011.6017518 
Pei, Y., A.F. May and G.J. Snyder, 2011. Self-tuning the carrier concentration of $\mathrm{PbTe} / \mathrm{Ag} 2 \mathrm{Te}$ composites with excess ag for high thermoelectric performance. Adv. Energy Mater., 1: 291-296. DOI: $10.1002 /$ aenm.201000072

Rowe, D.M. and G. Min, 1996. Design theory of thermoelectric modules for electrical power generation. IEE Proc. Sci. Meas. Technol., 143: 351-356. DOI: 10.1049/ip-smt:19960714

Tripathi, M.N. and C.M. Bhandari, 2005. Material parameters for thermoelectric performance. Pramana, 65: 469-479. DOI: 10.1007/BF02704204

Weidenkaff, A., M.H. Aguirre, L. Bocher, M. Trottmann and P. Tomes et al., 2010. Development of perovskite-type cobaltates and manganates for thermoelectric oxide modules. J. Korean Ceramic Society, 47: 47-53.

DOI: $10.4191 /$ KCERS.2010.47.1.047
Xiong, W., I. Boniche and D.P. Arnold, 2011. Micromachined radial thermoelectric modules for power generation using hot gas streams. J. Microelectromech. Syst., 20: 512-521.

DOI: 10.1109/JMEMS.2011.2112336

Yasukawa, M., Y. Hamada, T. Kono, K. Ueda and H. Yanagi et al., 2010. Thermoelectric properties of Ptype $\mathrm{BaSnO}_{3}$ Ceramic Doped with Cobalt. J. Japan Society Powder Powder Metallurgy, 58: 149-154. DOI: $10.2497 / \mathrm{jj}$ spm.58.149 